\title{
Investigation of Possible Wellbore Cement Failures During Hydraulic Fracturing Operations
}

\author{
Jihoon Kim $^{\mathrm{a}, \mathrm{b}}$, George J. Moridis ${ }^{\mathrm{b}}$, Eduardo R. Martinez ${ }^{\mathrm{a}}$ \\ ${ }^{a}$ Harold Vance Department of Petroleum Engineering, Texas A\&M University. 3116 TAMU Richardson Building College Station, TX \\ 77843, USA \\ ${ }^{b}$ Earth Sciences Division, Lawrence Berkeley National Laboratory. 1 Cyclotron Road 90R1116, Berkeley, CA 94720, USA
}

\begin{abstract}
We model and assess the possibility of shear failure along the vertical well by using the Mohr-Coulomb failure model and employing a rigorous coupled flow-geomechanic analysis. To this end, we take various values of cohesion between the well casing and the surrounding cement to represent different quality levels of cementing operation (low cohesion corresponds to low-quality cement and/or incomplete cementing). The simulation results show that there is very little fracturing when the cement is of high quality. Conversely, incomplete cementing and/or weak cement can causes significant shear failure and evolution of long fractures/cracks along the vertical well. Specifically, low cohesion between the well and cemented areas can cause significant shear failure along the well, while high cohesion does not cause shear failure. The Biot and thermal dilation coefficients strongly affect shear failure along the well casing, and low Young's modulus causes fast failure propagation. Still, for the high quality of the cementing job, failure propagates very little. When the hydraulic fracturing pressure is high or when permeability increases significantly, low cohesion of the cement can causes fast propagation of shear failure and of the resulting fracture/crack, but a high-quality cement with no weak zones exhibits limited shear failure that is only concentrated near the bottom of the vertical part of the well. Thus, high-quality cement and complete cementing along the vertical well appears to be the strongest protection against shear failure of the wellbore cement and, consequently, against contamination hazards to drinking water aquifers during hydraulic fracturing operations.
\end{abstract}

Keywords: Well instability, Cement failure, Hydraulic fracturing, Shale gas, Coupled flow and geomechanics

Email addresses: jihoon. kimetamu.edu (Jihoon Kim), GJMoridis@lbl.gov (George J. Moridis), waldo49@tamu.edu (Eduardo R. Martinez) 


\section{Introduction}

Gas production from shale gas reservoirs has become an important energy resource in the future, due to the abundant amount of gas (Arthur and Layne, 2008; Jenkins and Boyer, 2008). However, extreme low permeability of the shale gas reservoirs requires artificial reservoir stimulation to enhance productivity, such as hydraulic fracturing (Hill and Nelson, 2000; Vermylen and Zoback, 2011). At the same time, environmental impacts induced by the hydraulic fracturing have been raised, for example, contamination of ground water, unstable growth of the hydraulic fractures, seismic risks and reactivation of existing faults, and soil contamination due to proppant chemicals (Zoback et al., 2010; Rutqvist et al., 2013, 2015).

Dusseault et al. (2001) also studied compaction-induced shear failure of the vertical well by fluid production. Shear failure is one of the typical mechanisms of well instability. Incomplete cementing between the well and reservoir formations is considered as one of the high environmental risks of ground water contamination (Zoback et al., 2010). Pressurization at the bottom of the vertical well causes high shear stress along the vertical well and can result in shear slip at the contacting area between the well casing and the cemented zone when the contacting area is poorly cemented. Cracks from shear failure along the well can be a potential path way that can connect deep shale gas reservoirs to shallow aquifers, yielding high permeability.

Failure induced by perturbation of fluid pressure implies strong interaction between flow and geomechanics, and thus coupled flow-geomechanics simulation is required for accurate prediction and better assessment of potential risks induced by shear failure along the well. Pressure of incompressible fluid such as water is sensitive to small change in pore volume, and, in turn, the changes in pressure alter the effective stress regime, which induces material failure (e.g., Kim et al. (2012)). Permeability is also a strong function of the failure status, because material failure creates fractures, which increases permeability significantly by several orders (Bandis et al., 1983; Rutqvist and Stephansson, 2003; Min et al., 2004). Thus, in this study, we rigorously model two-way coupled flow and geomechanics with dynamic failure-dependent permeability.

For the modeling of coupled flow and geomechanics, we use a sequential implicit method, employing the fixed-stress split, which can provide unconditional stability and high accuracy, considering two-way coupling between flow and geomechanics (Kim et al., 2011). Specifically, flow is solved first, fixing the total stress fields and considering the contribution of geomechanics to flow explicitly, and then geomechanics is solved from the solutions obtained at the previous flow step. We employ finite volume and finite element methods for flow and 
geomechanics in space discretization, respectively, and the backward Euler method in time discretization. We employ the Mohr-Coulomb failure model for elastoplasticity, which is widely used to model failure in cohesive frictional materials, shear failure. We then use dynamic permeability to reflect failure status every time steps. In this study, from various numerical simulations, we will find that there is very little fracturing when the cementing is complete and well-done, whereas incomplete cementing can causes significant shear failure along the vertical well.

\section{Mathematical description}

We first describe governing equations for fluid-heat flow and geomechanics, respectively, followed by couplings in pore volume and permeability. The governing equation for multiphase and multi-component flow comes from mass balance as, (e.g., Pruess et al. (1999)),

$$
\frac{d}{d t} \int_{\Omega} m^{k} d \Omega+\int_{\Gamma} \mathbf{f}^{k} \cdot \mathbf{n} d \Gamma=\int_{\Omega} q^{k} d \Omega
$$

where the superscript $k$ indicates the fluid component. $d(\cdot) / d t$ means the time derivative of a physical quantity $(\cdot)$ relative to the motion of the solid skeleton. $m^{k}$ is mass of component $k . \mathbf{f}^{k}$ and $q^{k}$ are its flux and source terms on the domain $\Omega$ with a boundary surface $\Gamma$, respectively, where $\mathbf{n}$ is the normal vector of the boundary. The fluid mass of component $k$ is written as

$$
m^{k}=\sum_{J} \phi S_{J} \rho_{J} X_{J}^{k}
$$

where the subscript $J$ indicates fluid phases. $\phi$ is the true porosity, defined as the ratio of the pore volume to the bulk volume in the deformed configuration. $S_{J}, \rho_{J}$, and $X_{J}^{k}$ are saturation and density of phase $J$, and the mass fraction of component $k$ in phase $J$, respectively.

The mass flux term is obtained from

$$
\mathbf{f}^{k}=\sum_{J}\left(\mathbf{w}_{J}^{k}+\mathbf{J}_{J}^{k}\right)
$$

where $\mathbf{w}_{J}^{k}$ and $\mathbf{J}_{J}^{k}$ are the convective and diffusive mass flows of component $k$ in phase $J$. For the liquid phase, $J=L, \mathbf{w}_{J}^{k}$ is supplemented by Darcy's law, which includes the Klinkenberg effect for the case of gas. $\mathbf{J}_{J}^{k}$ is determined by Fick's law with diffusion and hydrodynamic dispersion.

Heat flow comes from energy (heat) balance, as

$$
\frac{d}{d t} \int_{\Omega} m^{H} d \Omega+\int_{\Gamma} \mathbf{f}^{H} \cdot \mathbf{n} d \Gamma=\int_{\Omega} q^{H} d \Omega
$$


where the superscript $H$ indicates the heat component. $m^{H}, \mathbf{f}^{H}$, and $q^{H}$ are heat, its flux, and source terms, respectively. The term $m^{H}$ is the heat accumulation term, and is expressed as

$$
m^{H}=(1-\phi) \int_{T_{0}}^{T} \rho_{R} C_{R} d T+\sum_{J} \phi S_{J} \rho_{J} e_{J}
$$

where $\rho_{R}, C_{R}, T$ and $T_{0}$ are density, heat capacity, temperature of the porous medium, and reference temperature. $e_{J}$ denotes specific internal energy of phase $J$. The heat flux is written as

$$
\mathbf{f}^{H}=-\mathbf{K}_{H} \operatorname{Grad} T+\sum_{J} h_{J} \mathbf{w}_{J}
$$

where $\mathbf{K}_{H}$ is the composite thermal conductivity of the porous media. Grad is the gradient operator. The specific internal energy, $e_{J}$, and enthalpy, $h_{J}$, in phase $J$ become, respectively,

$$
e_{J}=\sum_{k} X_{J}^{k} e_{J}^{k}, \quad h_{J}=\sum_{k} X_{J}^{k} h_{J}^{k}
$$

Geomechanics is based on the quasi-static assumption (Coussy, 1995), written as

$$
\operatorname{Div} \boldsymbol{\sigma}+\rho_{b} \mathbf{g}=\mathbf{0},
$$

where Div is the divergence operator. $\boldsymbol{\sigma}$ is the total stress tensor, and $\rho_{b}$ is the bulk density. Tensile stress is positive in this study. The infinitesimal transformation is used to allow the strain tensor, $\varepsilon$, to be the symmetric gradient of the displacement vector, $\mathbf{u}$,

$$
\varepsilon=\frac{1}{2}\left(\operatorname{Grad}^{T} \mathbf{u}+\mathbf{G r a d} \mathbf{u}\right)
$$

Then, considering mass, energy, linear momentum balances, we focus on non-isothermal multiphase flow (i.e., water-gas flow) with the elastoplastic geomechanics in this study, using the following constitutive relations of thermo-poro-mechanics.

\section{Shear failure and coupling in permeability and porosity}

Leaking of the injected water induces pressurization near the wells, as shown in Figure 1. Pressurization at the bottom of the vertical well causes high shear stress along the vertical well and can result in shear slip at the contacting area between the well casing and the cemented zone when the contacting area is poorly cemented. Shear failure along the well can create high permeable area that can connect deep shale gas reservoirs to the aquifers. 
For the modeling of shear failure in this study, we use the Mohr-Coulomb model, which is widely used to model failure of cohesive frictional materials. The Mohr-Coulomb model is given as

$$
\begin{gathered}
f=\tau_{m}^{\prime}-\sigma_{m}^{\prime} \sin \Psi_{f}-c_{h} \cos \Psi_{f} \leq 0, \quad g=\tau_{m}^{\prime}-\sigma_{m}^{\prime} \sin \Psi_{d}-c_{h} \cos \Psi_{d} \leq 0 \\
\sigma_{m}^{\prime}=\frac{\sigma_{1}^{\prime}+\sigma_{3}^{\prime}}{2} \quad \text { and } \quad \tau_{m}^{\prime}=\frac{\sigma_{1}^{\prime}-\sigma_{3}^{\prime}}{2}
\end{gathered}
$$

where $\sigma_{1}^{\prime}, \sigma_{2}^{\prime}$, and $\sigma_{3}^{\prime}$ are the maximum, intermediate, and minimum principal effective stresses. $c_{h}$ is is the cohesion. $f$ and $g$ are the yield and plastic potential functions, respectively. $\Psi_{f}$, and $\Psi_{d}$ are the friction angle, and the dilation angle, respectively.

Once shear failure occurs, we employ the permeability model motivated by the cubic law (Witherspoon et al., 1980; Rutqvist and Stephansson, 2003) for the created fracture, written as (e.g., for the case of single water phase),

$$
Q_{w}=a_{c} \frac{\omega^{3}}{12 \mu_{w}} H\left(\operatorname{Grad} p_{w}-\rho_{w} \mathbf{g}\right)
$$

where $\omega$ is the fracture opening (aperture) and $H$ is the fracture plate width. $Q_{w}, \mu_{w}$ and $\rho_{w}$ are flow rate, viscosity, and density of water, respectively. $a_{c}$ is the correction factor reflecting the fracture roughness. $\omega$ consists of the residual hydraulic aperture $\left(\omega_{r}\right)$, the opening of fracture deformation $\left(\omega_{m}\right)$, and shear dilation $\left(\omega_{d}\right)$ (Min et al., 2004). $\omega_{m}+\omega_{d}$ is obtained directly from displacement of geomechanics solution. Even though $\omega_{d}$ and $\omega_{m}$ are negligible due to strong compression, $\omega_{r}$ can increase the permeability significantly for extremely low permeable reservoirs.

For modeling relative permeability and capillarity, we use a modified version of Stone's relative permeability model (Aziz and Settari, 1979) and the van Genutchen capillary pressure model (van Genuchten, 1980), respectively, written as

$$
\begin{aligned}
k_{r, J} & =\max \left\{0, \min \left\{\left(\frac{S_{J}-S_{i r, J}}{1.0-S_{i r, w}}\right)^{n_{k}}, 1\right\}\right\} \\
P_{c} & =\Pi_{c}\left(\left(S^{e}\right)^{-1 / \lambda_{p}}-1\right)^{1-\lambda_{p}}, S^{e}=\frac{S_{w}-S_{i r, w}}{1-S_{i r, g}-S_{i r, w}}
\end{aligned}
$$

where $k_{r, J}, S_{i r, J}$, and $n_{k}$ are relative permeability of phase $J$, irreducible saturation of phase $J$, and the exponent that characterizes the relative permeability curve, respectively. $P_{c}, \lambda_{p}$ and $\Pi_{c}$ are capillary pressure, the exponent that characterizes the capillary pressure curve, and the capillary modulus, respectively. Then, for the reference case, we take $S_{i r, w}=0.08, S_{i r, g}=0.01$, and $n_{k}=4.0$ for relative permeability, and $\lambda_{p}=0.45$, 
$S_{i r, w}=0.05, S_{i r, g}=0.0$, and $\Pi_{c}=2.0 \mathrm{kPa}$ for capillarity, where smaller $S_{i r, w}$ and $S_{i r, g}$ of the capillarity model are chosen in order to prevent unphysical behavior (Moridis et al., 2008). We also employ the equivalent pore-pressure concept for multiphase flow coupled with geomechanics,(Coussy, 2004), not using the average pore-pressure concept. For strong capillarity, the equivalent pore-pressure provides high accuracy and stability, whereas the average pore-pressure may cause large numerical errors (Kim et al., 2013).

We employ the constitutive relations for coupled multiphase non-isothermal flow and elastoplastic geomechanics, described in Coussy (1995). For elastoplastic mechanics and nonisothermal multiphase flow, the constitutive relations are written as

$$
\begin{aligned}
\delta \boldsymbol{\sigma} & =\underbrace{\mathbf{C}_{d r}: \delta \varepsilon}_{\delta \boldsymbol{\sigma}^{\prime}}-\alpha_{J} \delta p_{J} \mathbf{1}-3 \alpha_{T} K_{d r} \delta T \mathbf{1} \\
\left(\frac{\delta m}{\rho}\right)_{J} & =\alpha_{J} \delta \varepsilon_{v}+N_{J K} \delta p_{K}-3 \alpha_{m, J} \delta T \\
\delta \bar{S} & =\bar{s}_{J} \delta m_{J}+3 \alpha_{T} K_{d r} \delta \varepsilon_{v}-3 \alpha_{m, J} \delta p_{J}+\frac{C_{d}}{T} \delta T
\end{aligned}
$$

where $\mathbf{C}_{d r}$ is the drained-isothermal elastic moduli, $\mathbf{N}=\left\{N_{J K}\right\}$ is the inverse matrix of the Biot moduli $\mathbf{M}=\left\{M_{J K}\right\}$ (i.e., $\mathbf{N}=\mathbf{M}^{-1}$ ), where $\mathbf{N}$ and $\mathbf{M}$ are positive definite. The Biot coefficient $\alpha_{J}$ for multiphase flow takes $\alpha_{J}=\alpha S_{J}$, where $\alpha$ is the Biot coefficient for single phase flow (Biot and Willis, 1957). We define $\boldsymbol{\sigma}^{\prime}$, the effective stress, in the incremental form as $\delta \boldsymbol{\sigma}^{\prime}=\mathbf{C}_{d r}: \delta \varepsilon$, where $\boldsymbol{\sigma}^{\prime}=\mathbf{0}$ at $\boldsymbol{\varepsilon}=\mathbf{0}$. $3 \alpha_{T}$ is the volumetric skeleton thermal dilation coefficient, $K_{d r}$ is the drained isothermal bulk modulus, $\mathbf{1}$ is the rank2 identity tensor, $\varepsilon_{v}$ is the total volumetric strain, and $3 \alpha_{m, J}=3 \alpha_{\phi}+\phi 3 \alpha_{J}$, where $3 \alpha_{\phi}$ and $3 \alpha_{J}$ are the coefficients of thermal dilation related to porosity and phase $J$, respectively. $\bar{s}_{J}$ is the internal entropy per unit mass of phase $J$ (i.e., specific entropy of phase $J$ ). $C_{d}=C+m_{J} C_{p, J}$ is the total volumetric heat capacity, where $C$ is the skeleton volumetric heat capacity and $C_{p, J}$ is the volumetric specific heat capacity at constant pressure for phase $J$. Double indices in Equations $15-17$ indicate summation. $\delta$ implies variation relative to the motion of the solid skeleton.

For a two-phase fluid system (such as gas and water), an appropriate (i.e., admissible) N, which is typically used in engineering, is given as (e.g., Lewis and Schrefler (1998)) 


$$
\mathbf{N}=\left[\begin{array}{cc}
\phi S_{g} c_{g}-\phi \frac{d S_{w}}{d p_{c g}}+S_{g} \frac{b-\phi}{K_{s}} S_{g} & \phi \frac{d S_{w}}{d p_{c g}}+S_{g} \frac{b-\phi}{K_{s}} S_{w} \\
\phi \frac{d S_{w}}{d p_{c g}}+S_{w} \frac{b-\phi}{K_{s}} S_{g} & \phi S_{w} c_{w}-\phi \frac{d S_{w}}{d p_{c g}}+S_{w} \frac{b-\phi}{K_{s}} S_{w}
\end{array}\right],
$$

where the subscript $(\cdot)_{g}$ indicates the gas phase, $c_{J}$ is the compressibility of the fluid phase $J, p_{c g}$ is the capillary pressure between gas and water, and $K_{s}$ is the intrinsic solid grain bulk modulus.

\section{Numerical Implementation}

We employ the finite volume and finite element methods for flow and geomechanics in space discretization, respectively, which are widely used in reservoir and geotechnical engineerings, respectively (Aziz and Settari, 1979; Lewis and Schrefler, 1998). For time discretization, we use the backward Euler method, which is typically used in reservoir simulation. We use TOUGH+RealGasH2O as a fluid and heat flow simulator and ROCMECH for a geomechanics simulator, namely $\mathrm{T}+\mathrm{M}$, developed in the Lawrence Berkeley National Laboratory (Kim and Moridis, 2013), using a sequential implicit method, called the fixed-stress sequential method. T+M has been verified for physical problems such as the Terzaghi, Mandel, McNamee-Gibson problems, and validated with various scenarios that have rigorous coupled flow and geomechanics (Kim et al., 2012; Kim and Moridis, 2014).

Sequential methods can offer the use of existing robust flow and geomechanics simulators only by constructing an interface between them. According to Kim et al. (2011), the fixed stress sequential method can provide unconditional stability and high accuracy, comparable to the fully coupled methods. The fixed-stress method solves the flow problem, fixing the total stress field, where the strain and displacement fields can be changed, and considering the contribution of geomechanics to flow explicitly. Then, it solves geomechanics, based on the solutions obtained at the previous flow problem. This sequential method can easily be implemented by the Lagrange porosity function $\Phi$ and its correction $\Delta \Phi$, written as a form of the staggered approach as,

$$
\Phi^{n+1}-\Phi^{n}=\underbrace{\left(\frac{\alpha^{2}}{K_{d r}}+\frac{\alpha-\Phi^{n}}{K_{s}}\right)}_{\Phi^{n} c_{p}} \sum_{J} S_{J}^{n+1}\left(p_{J}^{n+1}-p_{J}^{n}\right)+3 \alpha_{T} \alpha\left(T^{n+1}-T^{n}\right)-\underbrace{\left(\sigma_{v}^{n}-\sigma_{v}^{n-1}\right)}_{\Delta \Phi},
$$

where $c_{p}$ is the pore compressibility in conventional reservoir simulation (Aziz and Settari, 1979), and $\sigma_{v}$ is the total (volumetric) mean stress. $\Phi$ is defined as the ratio of the pore volume in the deformed configuration to 
the bulk volume in the reference (initial) configuration. The porosity correction term, $\Delta \Phi$, is calculated from geomechanics, which corrects the porosity estimated from the pore compressibility. The fixed-stress sequential method solves two-way coupling between flow and geomechanics, so it captures the Mandel-Cryer effects, solving Mandel's problem correctly, which cannot be simulated by the uncoupled simulation.

\section{Numerical Results}

We have a full 3D domain of numerical simulation in geomechanics, as shown in Figure 2, taking a zone near the vertical well (i.e., cylindrical domain). The discretized domain has $20 \times 4 \times 50$ grid blocks in the radial (' $r$ '), angular (' $\theta$ '), and vertical (' $z$ ') directions, respectively. We use a uniform grid discretization in the $z$ direction, where the spacing of a gridlock is $3 \mathrm{~m}$, while different grid spacings are used horizontally (cylindrical coordinate). Specifically, the cylindrical discretization starts with $0.06 \mathrm{~m}$ off the origin in the radial direction, which implies that the diameter of the well casing is $0.12 \mathrm{~m}$. Then, the grid spacings from the well casing are $0.01 \mathrm{~m}, 0.01 \mathrm{~m}, 0.02 \mathrm{~m}, 0.02 \mathrm{~m}, 0.04 \mathrm{~m}, 0.08 \mathrm{~m}, 0.16 \mathrm{~m}$ from the first to the 7 th layers, and uniformly $0.3 \mathrm{~m}$ from the 8 th to 19 th layers, and $1.0 \mathrm{~m}$ for the 20th layers. In this domain of simulation, the horizontal well is assumed to be placed vertically $90 \mathrm{~m}$ from top $(\mathrm{z}=-1440 \mathrm{~m})$ and changed horizontally perpendicular to the direction of the minimum compressive total stress. The area of the vertical well from $-1431 \mathrm{~m}$ to $-1440 \mathrm{~m}$ is assumed to be open, having high permeability, $2.56 \times 10^{-11} \mathrm{~m}^{2}$ (25.9 Darcy), where 1 Darcy is $9.87 \times 10^{-13} \mathrm{~m}^{2}$. This equivalent permeability corresponds to $a_{c}=0.9$ and $\omega=0.15 \mathrm{~mm}$. From Bandis et al. (1983), $\omega=0.15 \mathrm{~mm}$ is considered an appropriate initial aperture between the open well and the reservoir. On the other hand, we take the 2D multiple interacting continuum (MINC) method along the surface of the vertical well (Figure 3), where fluid flows along a created fracture surface of shear failure. In the MINC model, fluid flows though the fracture medium over the domain, while the rock matrix medium stores fluid and conveys it to the fracture medium (Pruess and Narasimhan, 1985). The volumes of the five interacting continua correspond to those of the 5 gridblocks in the radial direction, excluding the well-casing part (the first gridblock) and taking the second gridblock to the sixth gridblock, as shown in Figure 3 (right). Then, the domain of flow is smaller than that of geomechanics.

The initial pressure is $17.10 \mathrm{MPa}$ at $1350 \mathrm{~m}$ in depth with the $12.44 \mathrm{kPa} / \mathrm{m}$ gradient. Initial gas and water saturations are 0.9 and 0.1 , respectively. Initial temperature is $58.75^{\circ} \mathrm{C}$ at $1350 \mathrm{~m}$ in depth with the $0.025^{\circ} \mathrm{C} / \mathrm{m}$ geothermal gradient. The heat capacities of the porous media, and the wet and dry thermal conductivities for all 
layers are $1000 \mathrm{~J} / \mathrm{kg} /{ }^{\circ} \mathrm{C}, 3.1 \mathrm{~W} / \mathrm{m} /{ }^{\circ} \mathrm{C}$, and $0.5 \mathrm{~W} / \mathrm{m} /{ }^{\circ} \mathrm{C}$, respectively. The initial permeability and porosity for rock (rock matrix) and cement are $8.645 \times 10^{-19} \mathrm{~m}^{2}$ and 0.076 , respectively. Thermodynamic properties of injected water and reservoir gas are determined by the given gas pressure, water saturation, and temperature, just as used in Moridis and Freeman (2014). We have no flow at the boundaries.

When material failure occurs, permeability can increase dramatically and discontinuously in time. Because we use the fixed grid system during simulation, the equivalent fracture permeability used in simulation can be written from Equation 12 as (Min et al., 2004)

$$
k_{p}=a_{c} \frac{\omega^{3}}{12 r_{0}}
$$

where $r_{0}$ is a grid spacing in the radial direction. The effect of shear dilation needs to be considered when the stress ratio $\left(\gamma_{s}\right)$ is higher than the critical stress ratio, $\gamma_{s}^{c}$, expressed as

$$
\gamma_{s}^{c}=\frac{1+\sin \Psi_{f}}{1-\sin \Psi_{f}}
$$

We then consider changes in permeability, using a permeability (or transmissibility) multiplier in $\eta_{p}$, as

$$
\eta_{p}\left\{\begin{array}{cc}
=1 & \text { if not failed } \\
\gg 1 & \text { if failed }
\end{array}\right.
$$

by which the intrinsic permeability, $k_{0}$ is expressed as $k_{0}=\eta_{p} k_{m}$, where $k_{m}$ is the intact rock or cement permeability. Thus, the permeability becomes a discontinuous function for a failure status. For the reference case, we first assume that the effects from $\omega_{m}$ and $\omega_{d}$ can be very small, being negligible. This assumption will be validated later in this study. Then, $\omega_{r}$ contributes to increasing the permeability. From Min et al. (2004), the fracture permeability varies from $5 \times 10^{-17} \mathrm{~m}^{2}$ to $1.0 \times 10^{-14} \mathrm{~m}^{2}$ under compression, and also has $\omega_{r}=5 \mu \mathrm{m}$. Thus, for the reference case, we take $\eta_{p}=10^{4}$, equivalent to the case of $a_{c}=0.9$ and $\omega_{r}=10.5 \mu m$, yielding $8.65 \times 10^{-15} \mathrm{~m}^{2}$.

For geomechanics, we have no horizontal displacement at the well bore side and constant traction at the outer boundary. The initial total principal stresses are -36.40MPa, -23.30MPa, and -29.12MPa at $1350 \mathrm{~m}$ in depth (top of the domain) in $\mathrm{x}, \mathrm{y}$, and $\mathrm{z}$ directions, respectively, where the corresponding stress gradients are $-27.0 \mathrm{kPa} / \mathrm{m},-$ $17.59 \mathrm{kPa} / \mathrm{m}$, and $-21.57 \mathrm{kPa} / \mathrm{m}$, respectively. Young's modulus and Poisson' ratio of rock matrix are $12 \mathrm{GPa}$ and 0.3 , respectively. The Biot coefficient, $\alpha$, is 0.8 . and the bulk densities are $2200 \mathrm{~kg} / \mathrm{m}^{3}$. The thermal dilation coefficients for all materials are $\alpha_{T}=4.5 \times 10^{-5 o} C^{-1}$. We consider generalized reservoir models, rather than 
selecting geomechanical properties for a certain specific reservoir. The geomechanical properties used in this study are within a range of the properties of shale gas reservoirs (Eseme et al., 2007; Sondergeld et al., 2010). The cohesion, friction and dilation angles of rock matrix for shear failure are $10.0 \mathrm{MPa}, \Psi_{f}=28.6^{\circ}(0.5 \mathrm{rad})$ and $\Psi_{d}=28.6^{\circ}(0.5 \mathrm{rad})$. For the well casing material such as steel, Young's modulus and Poisson's ratio are 200GPa and 0.3, respectively, and we assume no shear failure itself. For the cementing material, we refer to the properties of concrete (e.g., Onate et al. (1988)). Specifically, 30GPa and 0.2 are chosen for its Young modulus and Poisson's ratio for the reference case. The friction and dilation angles are $\Psi_{f}=28.6^{\circ}(0.5 \mathrm{rad})$ and $\Psi_{d}=28.6^{\circ}(0.5 \mathrm{rad})$, respectively. This $\Psi_{f}$ yields $\gamma_{s}^{c}=2.842$. Cohesion of the cement varies within a wide range: from 0.3MPa to 11MPa (Onate et al., 1988; Nawy, 2008; Ardiaca, 2009). Here, we assume that 10MPa or higher can provide complete cementing, and the cemented area has 10MPa of cohesion. We also take 30MPa of the constant bottom hole pressure for the reference case. From Baumgartner and Zoback (1989), the pressure at the injection point is between $15 \mathrm{MPa}$ and $30 \mathrm{MPa}$ after early time fracturing. The pressure shown in Rutqvist et al. (2015) varies from $30 \mathrm{MPa}$ to $40 \mathrm{MPa}$ for the reference case. Then, considering pressure drop between the injection point of the horizontal well and the bottom hole at the vertical well, 30MPa of the bottom hole pressure of the vertical well is assumed to be reasonable.

Then, we take various values of constant bottom hole pressure as well as cohesion of the contact zone between the well casing and the cement in order to test potential shear failure along the vertical well. The cohesion of the contact zone, which indicates quality of the cementing between the well casing and the cemented area, has 10MPa for complete cementing, while it is lower than 10MPa for the case of incomplete cementing. We take different cohesions of the contact zone, i.e., $0.3 \mathrm{MPa}, 0.5 \mathrm{MPa}, 1.0 \mathrm{MPa}, 2.0 \mathrm{MPa}, 5.0 \mathrm{MPa}, 10.0 \mathrm{MPa}$.

We find from Figure 4 that there is little shear failure when the cohesion is high (10.0MPa). However, as the cohesion is lower, the failed zone becomes larger, propagating upward along the vertical well. In particular, fracturing is biased to the direction of the minimum total stress, $S_{h}$. From the numerical results, it is possible to make a path where reservoir fluid can easily flow up to the shallow aquifers, creating cracked zones along the vertical well, when the cementing job is incomplete. Figure 5 (left) shows the propagation of shear failure. As the cohesion is lower, the failure propagation becomes faster. Although the failure propagation is fast, the injected water moves slowly along the fractured area, shown in Figure 5 (right). This indicates that gas fills the fractured area considerably. Once this fractured area is connected to the aquifer, reservoir gas can contaminate ground water. 
We identify shear failure at three monitoring points shown in Figure 6. For example, when shear failure occurs at P3 first, the permeability increases instantaneously from the permeability model of Equations 12 and 22. Accordingly, pressure also increases due to the enhanced permeability, shown in Figure 7. From Figure 8 (left), displacement normal to the contacted zone is below $0.5 \mu \mathrm{m}$. This implies that contribution of $\omega_{m}+\omega_{d}$ induced by mechanical deformation to permeability is negligible. The right of Figure 8 shows that there is almost no different in permeability between the reference case and the case of full consideration of the fracture opening. From Figure 7 (left), pressure varies from 17.1MPa to $20.5 \mathrm{MPa}$, and $\gamma_{s}$ accordingly ranges from 2.119 to 2.785 . We also find from Figure 7 (right) that pressures in most regions are below or around 20.68 MPa, which is a threshold for $\gamma_{s}$ to become $\gamma_{s}^{c}$. Then, $\gamma_{s}$ is less than $\gamma_{s}^{c}$, and contribution of $\omega_{d}$ induced by shear dilation to permeability is also negligible. These can validate the assumption that the increase of permeability in this study is mainly from $\omega_{r}$.

We investigate the case of larger poromechanical effects, taking $\alpha=1.0$. From Figure 9 (left), we find that the case of $b=1.0$ causes faster failure propagation, compared to the reference case $(\alpha=0.8)$. The higher value of Biot's coefficient reflects larger changes in effective stress for the same pressure change, and thus the high Biot's coefficient induces faster failure propagation. We also compare the reference case with the case of $\alpha_{T}=4.5 \times 10^{-8 o} C^{-1}$ (ignorance of thermal stress) to investigate the effect of thermal stress. Similarly to the test of Biot's coefficient, from Figure 9 (right), the larger thermal dilation coefficient causes the faster failure propagation, resulting in more sensitivity to the effective stress field.

Figure 10 shows comparison for the cases of two different Young's moduli for the contact zone as well as the cemented area. From the figure, 20GPa of Young's modulus causes faster propagation of shear failure than 30GPa of Young's modulus. Low Young's modulus implies low shear modulus, causing larger changes in shear deformation followed by shear effective stress. Then, low Young's modulus of the cement causes fast propagation of shear failure.

From Figure 11, when the bottom hole pressure is lowered to 20MPa, the failure propagation becomes slower, compared to the reference case. When we increase the bottom hole pressure up to 40MPa, the failure propagation becomes faster (Figure 12). Because the bottom hole pressure implies geomechanical loading, higher mechanical loading induces significant failure and fast failure propagation.

We investigate different permeability multipliers. Figure 13 shows failed zones for the cases of 5.0MPa and $10 \mathrm{MPa}$ of cohesion, when $\eta_{p}=10^{6}$, which increases nano-darcy of permeability to an order of darcy after 
failure. $\eta_{p}=10^{6}$ corresponds to a permeability for $a_{c}=0.9$ and $\omega_{r}=49 \mu m(0.876$ Darcy), having larger the residual hydraulic aperture than that of the reference case. As shown in Figure 13, the failed zone with $\eta_{p}=10^{6}$ becomes larger, compared to that with $\eta_{p}=10^{4}$ shown in Figure 4, because high permeability pressurizes the failed zone fast, which induces fast additional failure. However, 10.0MPa of cohesion hardly induces failure, same as that of Figure 4.

\section{Conclusion}

We investigated possibility of shear failure along the vertical well with rigorously coupled flow-geomechanic simulation. We varied values of cohesion between well casing and cemented areas, representing different degrees of cementing jobs. The simulation results showed that there was very little fracturing when the cementing was complete and well-done, whereas incomplete cementing caused significant shear failure along the vertical well. We found that poromechanical effects from changes in pressure and temperature strongly affect shear failure along the well casing. When Young's modulus is low, the upward failure propagation becomes fast. Still, for the high quality of the cementing job (complete cementing), little failure propagation was found. Even if the bottom hole pressure was increased, the complete well-cemented vertical well induced little fracturing. When the bottom hole pressure becomes lower, the fracture propagation due to weak cementing can be slower. From sensitivity test of permeability, the incomplete cementing induced different failure propagation, while the complete cementing did not cause additional failure.

In conclusion, the complete cementing along the vertical well is strongly suggested in order to avoid shear failure of the well. At the same time, the lower bottom hole pressure can slow fast failure propagation when shear failure occurs.

\section{Acknowledgements}

This study was supported by the US Environmental Protection Agency, Office of Water, under an Interagency Agreement with the U.S. Department of Energy at the Lawrence Berkeley National Laboratory through Contract No. DE-AC02-05CH11231, and by RPSEA (Contract No. 08122-45) through the Ultra-Deepwater and Unconventional Natural Gas and Other Petroleum Resources Research and Development Program as authorized by the US Energy Policy Act (EPAct) of 2005. The research described in this article has been funded wholly (or in part) by the U.S. Environmental Protection Agency through Interagency Agreement (DW-89- 
92235901-C) to the Lawrence Berkeley National Laboratory. The views expressed in this article are those of the author(s) and do not necessarily reflect the views or policies of the EPA.

\section{References}

Ardiaca D.H. 2009. Mohr-Coulomb parameters for modelling of concrete structures. Plaxis Bulletin 25: 12-15.

Arthur J.D. and Layne B.B.M. 2008. Hydraulic fracturing considerations for natural gas wells of the Marcellus shale. Ground Water Protection Council 2008 Annual Forum, Cincinati, Ohio.

Aziz K. and Settari A. 1979. Petroleum Reservoir Simulation. London: Elsevier.

Bandis S.C., Lumsden A.C., and Barton N. 1983. Fundamentals of Rock Joint Deformation. Int. J. Rock Mech. Min. Sci.Geomech. Abstr. 20(6): 249-268.

Baumgartner J. and Zoback M. 1989. Interpretation of hydraulic fracturing pressure-time records using interactive analysis methods. Int. J. Rock Mech. Min. Sci.Geomech. Abstr. 26(6): 461-469.

Biot M.A. and Willis D.G. 1957. The elastic coefficients of the theory of consolidation. J. Appl. Phys. 594-601.

Coussy O. 1995. Mechanics of porous continua. Chichester, England: John Wiley and Sons.

Coussy O. 2004. Poromechanics. Chichester, England: John Wiley and Sons.

Dusseault M., Bruno M., and Barrera J. 2001. Casing shear: Causes, cases, cures. SPE Drill. Completion 16: 98-107. SPE-72060-PA.

Eseme E., Urai J.L., Krooss B.M., and Littke R. 2007. Review of mechanical properties of oil shales: Implications for exploitation and basin modeling. Oil Shale 24(2): 159-174.

Hill D.G. and Nelson C.R. 2000. Gas productive fractured shales: an overviewand update. Gas TIPS 6(3): 4-13.

Jenkins C.D. and Boyer C.M. 2008. Coalbed- and shale-gas reservoirs. J. Pet. Technol. 92-99.

Kim J. and Moridis G.J. 2013. Development of the T+M coupled flow-geomechanical simulator to describe fracture propagation and coupled flow-thermal-geomechanical processes in tight/shale gas systems. Comput. Geosci. 60: 184-198. 
Kim J. and Moridis G.J. 2014. Gas flow tightly coupled to elastoplastic geomechanics for tight and shale gas reservoirs: material failure and enhanced permeability. SPEJ 19(6): 1110 - 1125. Spe 155640, http://dx.doi.org/10.2118/155640-PA.

Kim J., Sonnenthal E., and Rutqvist J. 2012. Formulation and sequential numerical algorithms of coupled fluid/heat flow and geomechanics for multiple porosity materials. Int. J. Numer. Meth. Engrg. 92: 425-456.

Kim J., Tchelepi H.A., and Juanes R. 2011. Stability and convergence of sequential methods for coupled flow and geomechanics: Fixed-stress and fixed-strain splits. Comput. Methods Appl. Mech. Engrg 200: 15911606.

Kim J., Tchelepi H.A., and Juanes R. 2013. Rigorous coupling of geomechanics and multiphase flow with strong capillarity. SPEJ 18(6): 1591-1606. Spe141268.

Lewis R.W. and Schrefler B.A. 1998. The finite element method in the static and dynamic deformation and consolidation of porous media. Chichester, England: Wiley, 2nd edition.

Min K.B., Rutqvist J., Tsang C.F., and Jing L. 2004. Stress-dependent permeability of fractured rock mass: a numerical study. Int. J. Rock Mecha. Min. Sci. 41: 1191-1210.

Moridis G. and Freeman C. 2014. The RealGas and RealGasH2O options of the TOUGH+ code for the simulation of coupled fluid and heat flow in tight/shale gas systems. Comput. Geosci. 65: 56-71.

Moridis G.J., Kowalsky M.B., and Pruess K. 2008. TOUGH+HYDRATE v1.0 User's Manual: A Code for the Simulation of System Behavior in Hydrate-Bearing Geologic Media. Report LBNL-00149E, Lawrence Berkeley National Laboratory, Berkeley, CA.

Nawy E.G. 2008. Concrete construction engineering handbook. Boca Raton, FL: Taylor and Francis.

Onate E., Oller S., Oliver J., and Lubliner J. 1988. A constitutive model for cracking of concrete based on the incremental theory of plasticity. Eng. Computation. 5(4): 309-319.

Pruess K. and Narasimhan T.N. 1985. A practical method for modeling fluid and heat flow in fractured porous media. SPEJ 25(1): $14-26$.

Pruess K., Oldenburg C., and Moridis G. 1999. TOUGH2 User's Guide, Version 2.0. Report LBNL-43134, Lawrence Berkeley National Laboratory, Berkeley, CA. 
Rutqvist J., Rinaldi A., Cappa F., and Moridis G. 2013. Modeling of fault reactivation and induced seismicity during hydraulic fracturing of shale-gas reservoirs. J. Pet. Sci. Eng. 107: 31-44.

Rutqvist J., Rinaldi A., Cappa F., and Moridis G. 2015. Modeling of fault activation and seismicity by injection directly into a fault zone associated with hydraulic fracturing of shale-gas reservoirs. J. Pet. Sci. Eng. In press, online Feb. doi:10.1016/j.petrol.2015.01.019.

Rutqvist J. and Stephansson O. 2003. The role of hydromechanical coupling in fractured rock engineering. Hydrogeol. J. 11: 7-40.

Sondergeld C.H., Newsham K., Comisky J., Rice M., and Rai C. 2010. Petrophysical considerations in evaluating and producing shale gas resources. Unconventional Gas Conference, Pittsburgh, PA.

van Genuchten 1980. A Closed-form Equation for Predicting the Hydraulic Conductivity of Unsaturated Soils. Soil Sci Soc Am J. (44): 892-898.

Vermylen J.P. and Zoback M. 2011. Hydraulic fracturing, microseismic magnitudes, and stress evolution in the Barnett Shale, Texas, USA. SPE Hydr. Frac. Tech. Conf., The woodland, TX, spe 140507.

Witherspoon P.A., Wang J.S.Y., Iwai K., and Gale J.E. 1980. Validity of Cubic Law for fluid flow in a deformable rock fracture. Water Resour. Res. 16(6): 1016-1024.

Zoback M., Kitasei S., and Copithorne B. 2010. Addressing the environmental risks from shale gas development. Worldwatch Institute Briefing Paper 1 (Worldwatch Inst., Washington D.C) . 


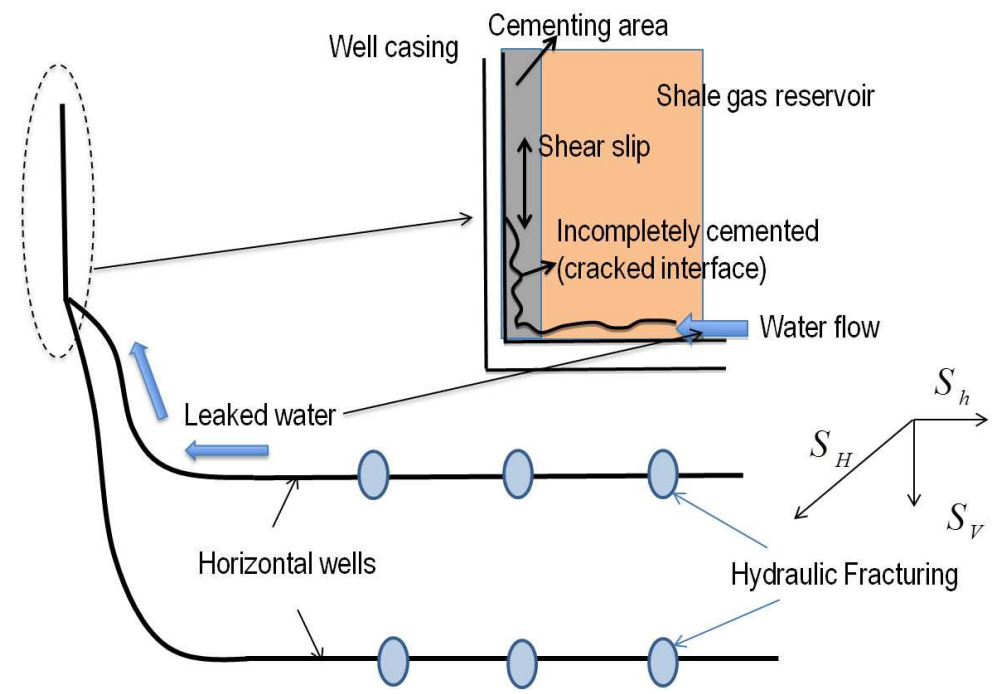

Figure 1: Schematics of shear failure along the vertical well. $S_{h}, S_{V}$, and $S_{H}$ are the minimum horizontal, vertical, maximum horizontal total stresses, respectively The increase of pressure at the bottom can increase shear stress, which can cause shear failure and slip along the well.

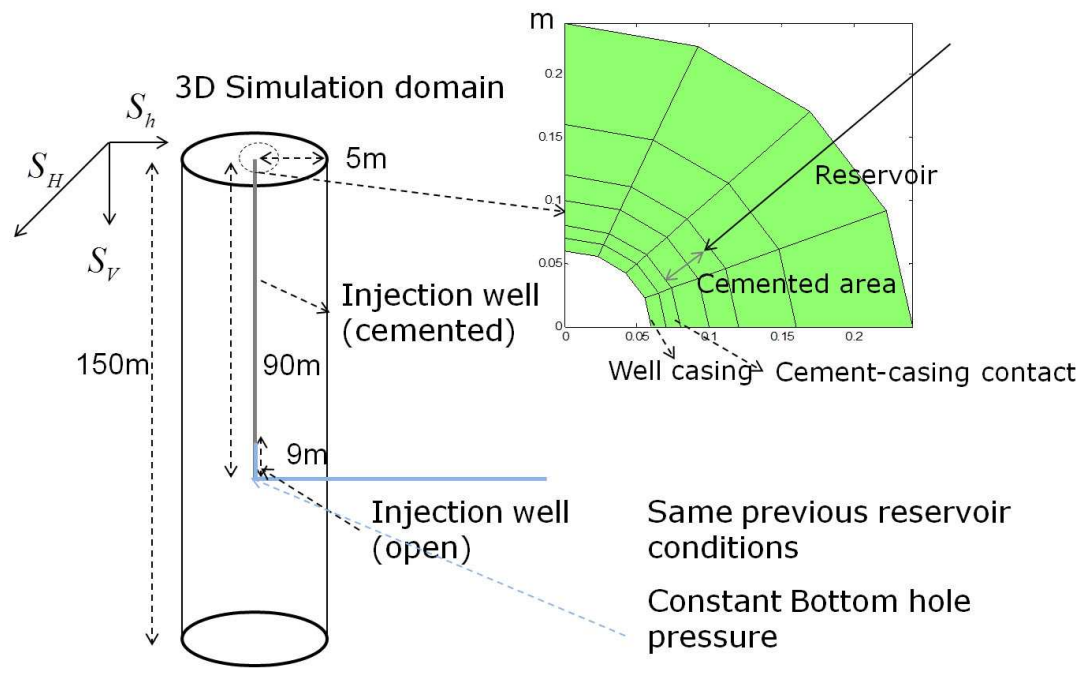

Figure 2: 3D simulation domain. We take a quarter of the cylindrical domain due to symmetry. Constant pressure due to leak from water injection is applied at $-1440 \mathrm{~m}$ of the vertical well. 


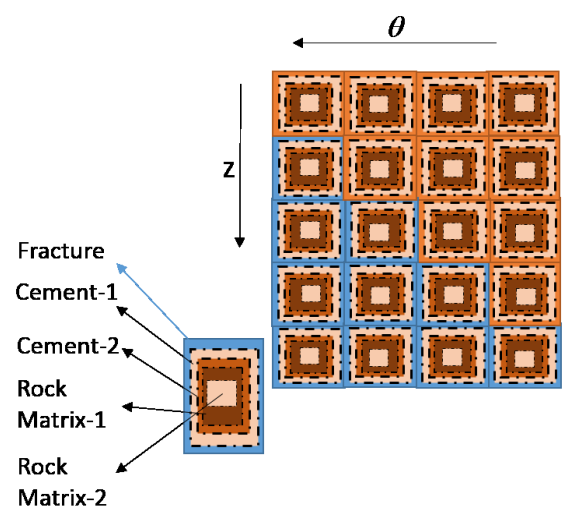

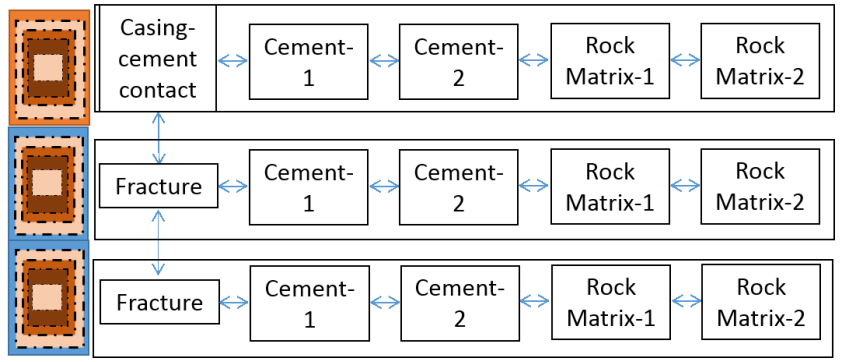

Figure 3: Left: A schematic diagram of 2D multiple interacting continuum method along the surface of the vertical well. Right: a conceptual model of the MINC model. ' $\leftrightarrow$ ' implies flow connectivity between materials. 'Casing-cement contact' is changed to 'Fracture' when shear failure occurs.
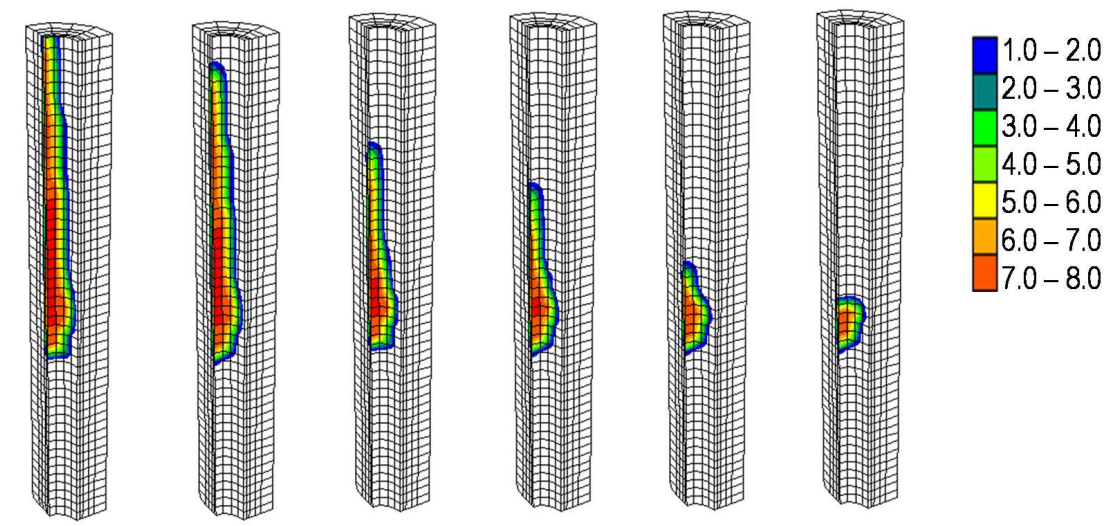

$c_{h}=0.3 \mathrm{MPa} \quad c_{h}=0.5 \mathrm{MPa}$

$c_{h}=1 M P a$

$c_{h}=2 M P a$

$c_{h}=5 M P a$

$c_{h}=10 \mathrm{MPa}$

Figure 4: Failed areas due to shear failure with various cohesion values. Little failure is found for high cohesion, while low cohesion causes large failed areas. The number in the color bar indicates Gauss-points of an element that experienced failure.

Table 1: Main input data for the reference case

\begin{tabular}{llll}
\hline Reservoir/cement permeability $\left(k_{p}\right)$ & $8.645 \times 10^{-19} \mathrm{~m}^{2}$ & Reservoir/cement Porosity $\left(\phi_{0}\right)$ & 0.076 \\
Reservoir Young's modulus $(E)$ & $12 \mathrm{GPa}$ & Reservoir Poisson's ratio $(\nu)$ & 0.3 \\
Cement Young's modulus $(E)$ & $30 \mathrm{GPa}$ & Cement Poisson's ratio $(\nu)$ & 0.2 \\
Well casing Young's modulus $(E)$ & $200 \mathrm{GPa}$ & Well casing Poisson's ratio $(\nu)$ & 0.3 \\
Bulk density $\left(\rho_{b}\right)$ & $2200 \mathrm{~kg} \mathrm{~m}{ }^{-3}$ & Initial pressure $\left(P_{i}\right)($ Top $)$ & $17.1 \mathrm{MPa}$ \\
Constant bottom hole pressure $\left(P_{b}\right)$ & $30 \mathrm{MPa}$ & Biot coefficient $(\alpha)$ & 0.8 \\
Initial temperature $\left(T_{i}\right)$ (Top) & $58.75^{\circ} \mathrm{C}$ & Thermal dilation coefficient $\left(\alpha_{T}\right)$ & $4.5 \times 10^{-5 \circ} \mathrm{C}^{-1}$ \\
Wet \& dry thermal conductivities & $3.1 \& 0.5\left(\mathrm{~W} / \mathrm{m} /{ }^{\circ} \mathrm{C}\right)$ & Heat capacity & $1000 \mathrm{~J} / \mathrm{kg} /{ }^{\circ} \mathrm{C}$ \\
Capillary modulus & $\Pi_{c}=2.0 \mathrm{kPa}$ & Exponents of $P_{c} \& k_{r, J}$ & $\lambda_{p}=0.45 \& n_{k}=4.0$ \\
\hline
\end{tabular}



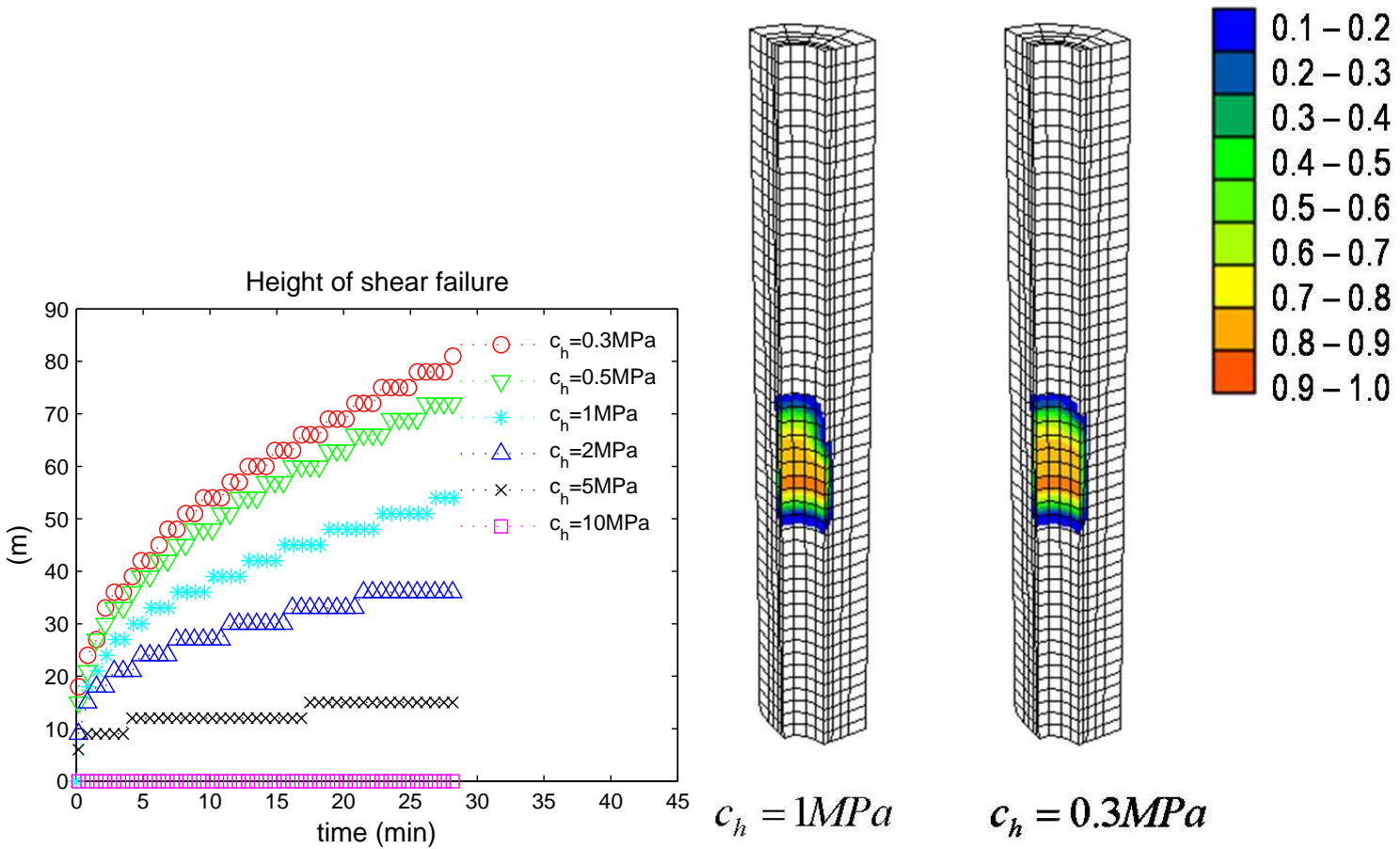

Figure 5: Left: Failure propagation from the bottom hole along the well at the side of the minimum total stress. The lower cohesion, the faster failure propagation. Right: Water saturation area higher than the initial water saturation. The number in the color bar indicates water saturation. Injected water only partially takes the failed area.
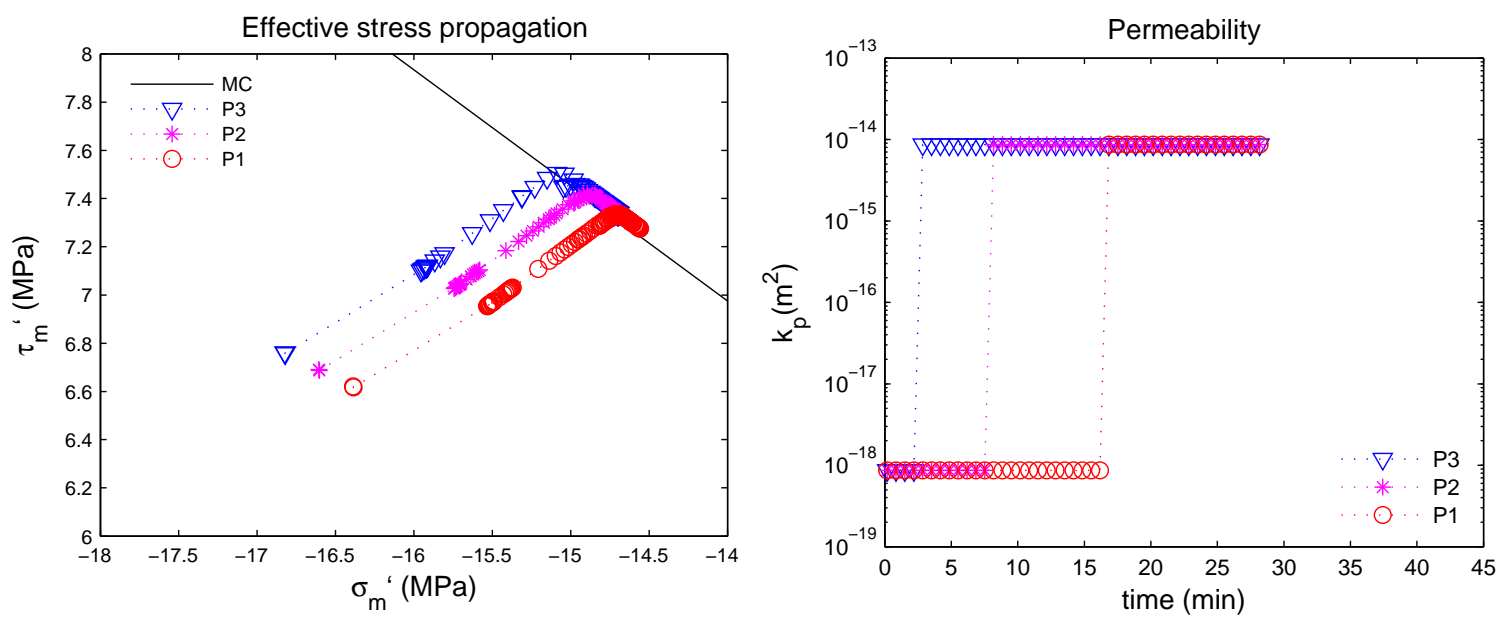

Figure 6: Evolution of effective stress (left) and permeability (right). 'MC' indicates the Mohr-Coulomb failure line. P1, $\mathrm{P} 2, \mathrm{P} 3$ are the monitoring point at $\mathrm{z}=-1363.5 \mathrm{~m}, \mathrm{z}=-1378.5 \mathrm{~m}, \mathrm{z}=-1393.5 \mathrm{~m}$, facing the direction of $S_{h}$, respectively. P3 first enters the plasticity regime, followed by P2 and P1. 

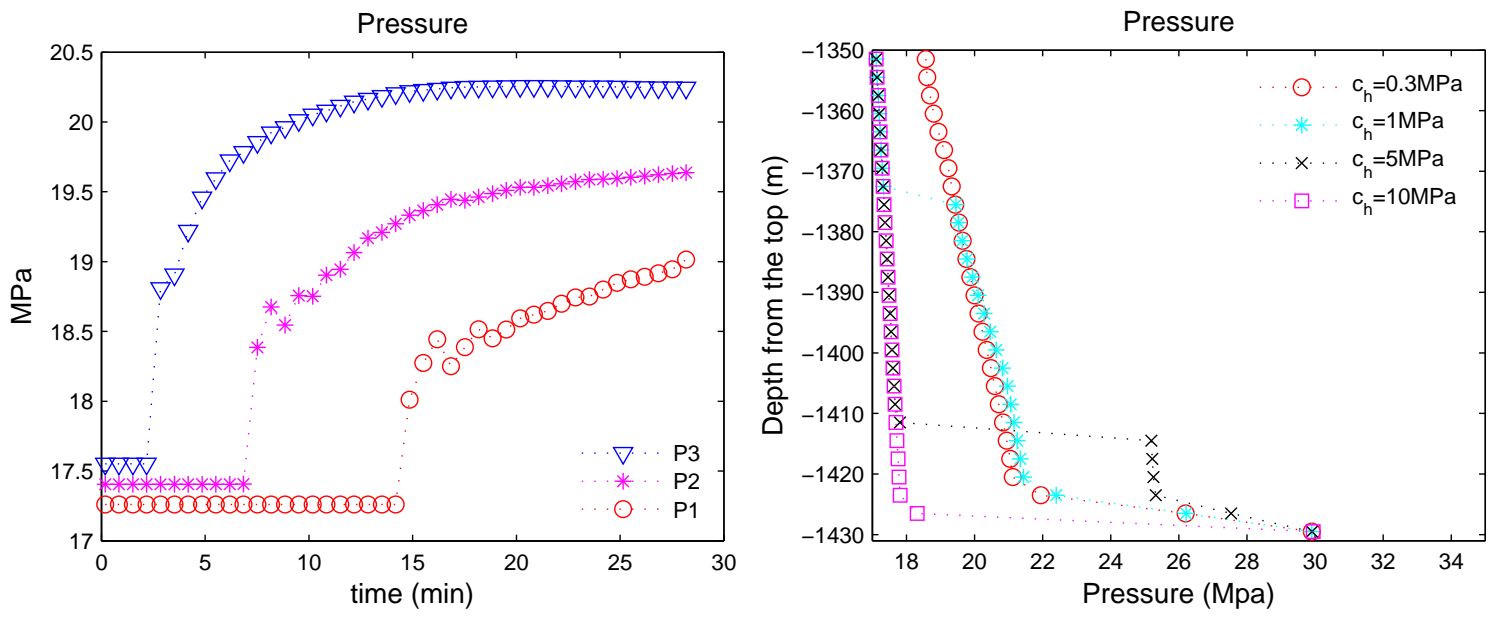

Figure 7: Left: Evolution of pressure for $c_{h}=0.3 M P a$. Right: Pressure distribution along the well. P3, P2, P1 are pressurized due to the enhanced permeability between the injection and monitoring points.
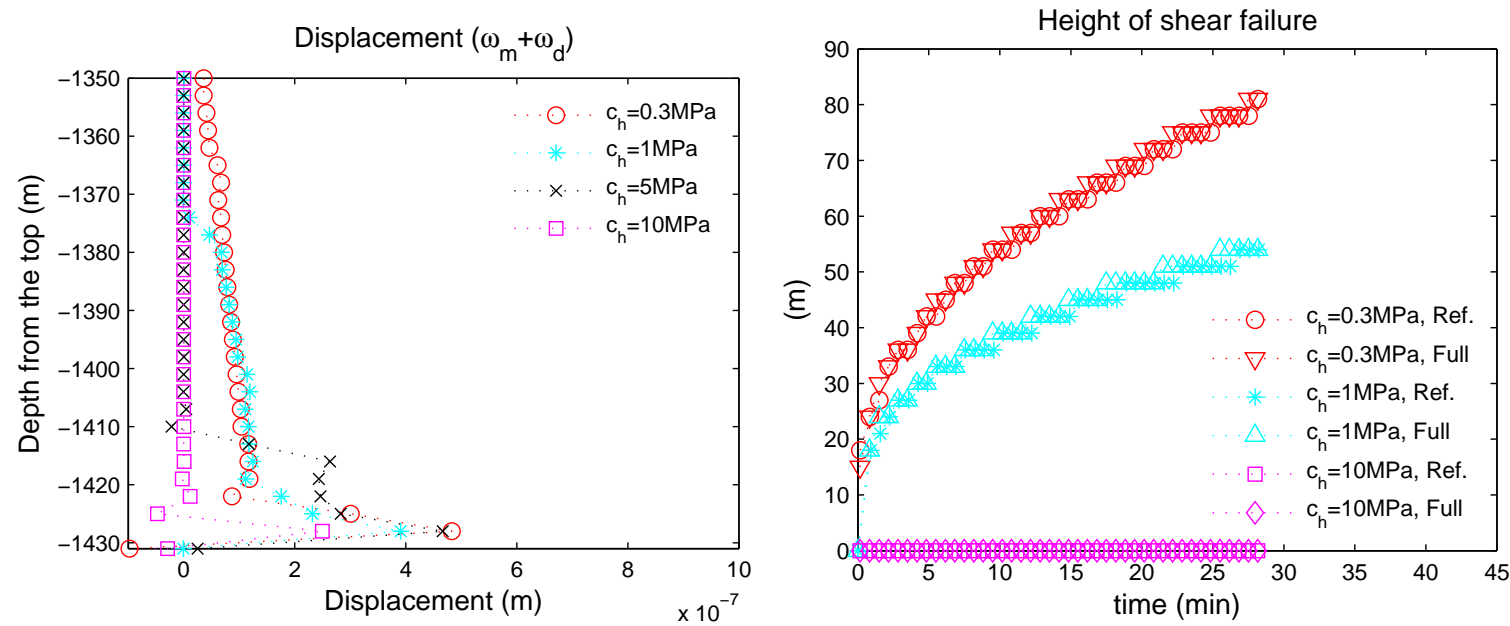

Figure 8: Left: Normal displacement to the contacted zone. Right: Failure propagation along the well. 'Full' indicates full consideration of the fracture opening in permeability. Contribution from $\left(\omega_{m}+\omega_{d}\right)$ is very small.
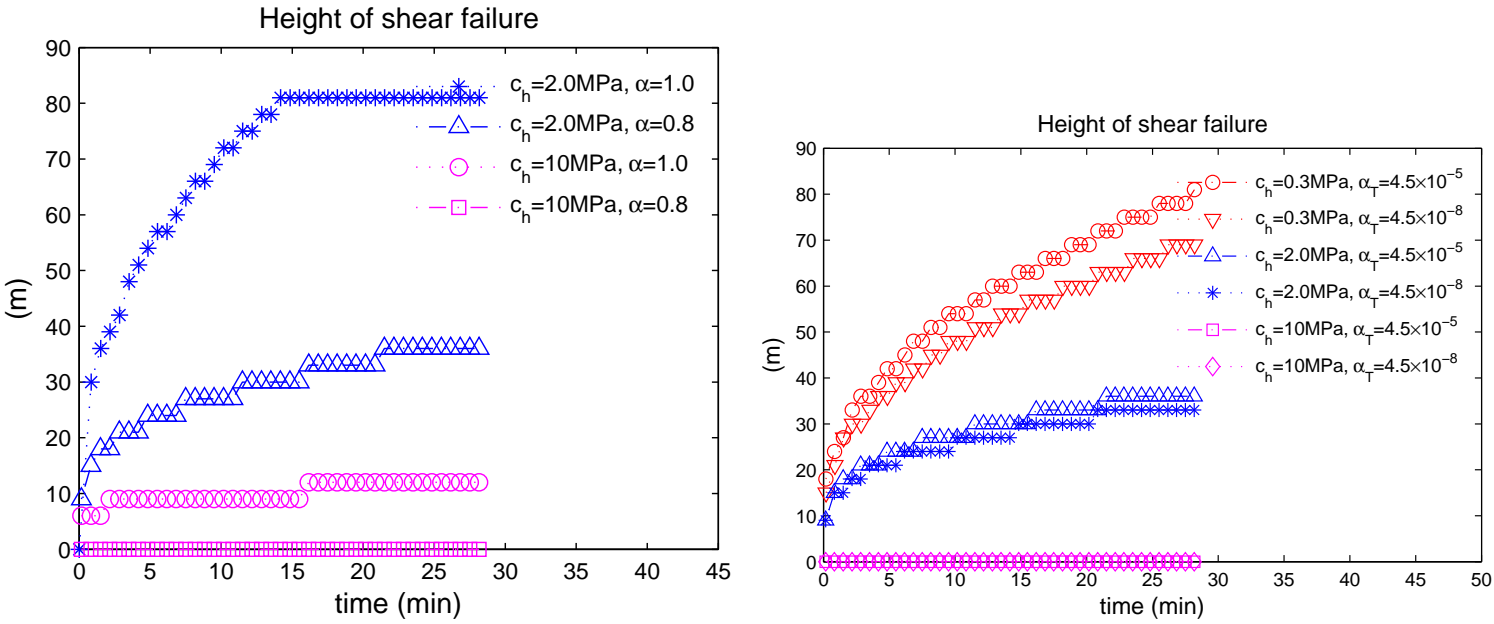

Figure 9: Left: Comparison between $\alpha=0.8$ and $\alpha=1.0$. Right: Comparison between $\alpha_{T}=4.5 \times 10^{-5 o} C^{-1}$ and $\alpha_{T}=4.5 \times 10^{-8 o} C^{-1}$. Poromechanical effects considerably affect the failure propagation. 


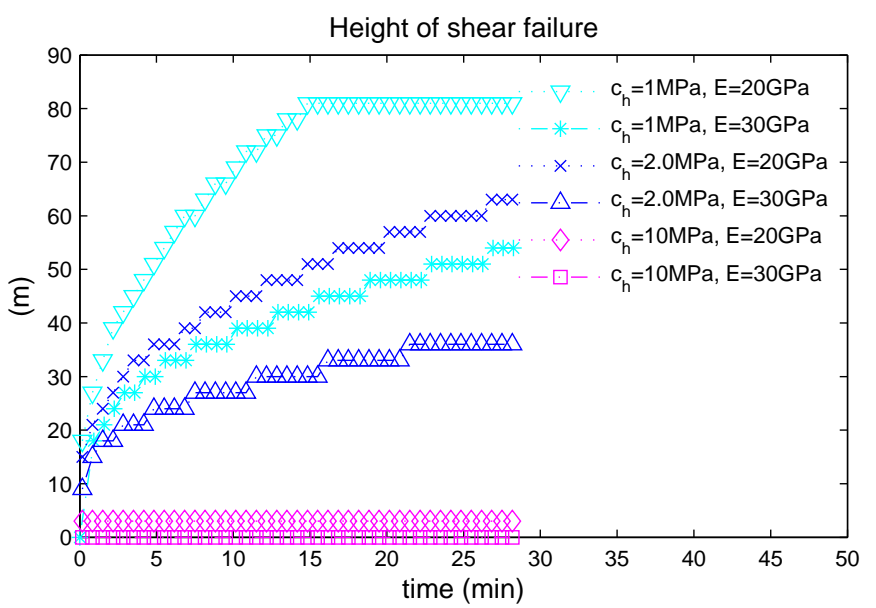

Figure 10: Comparison between $E=20 G P a$ and $E=30 G P a$. Low Young's modulus causes faster failure propagation.

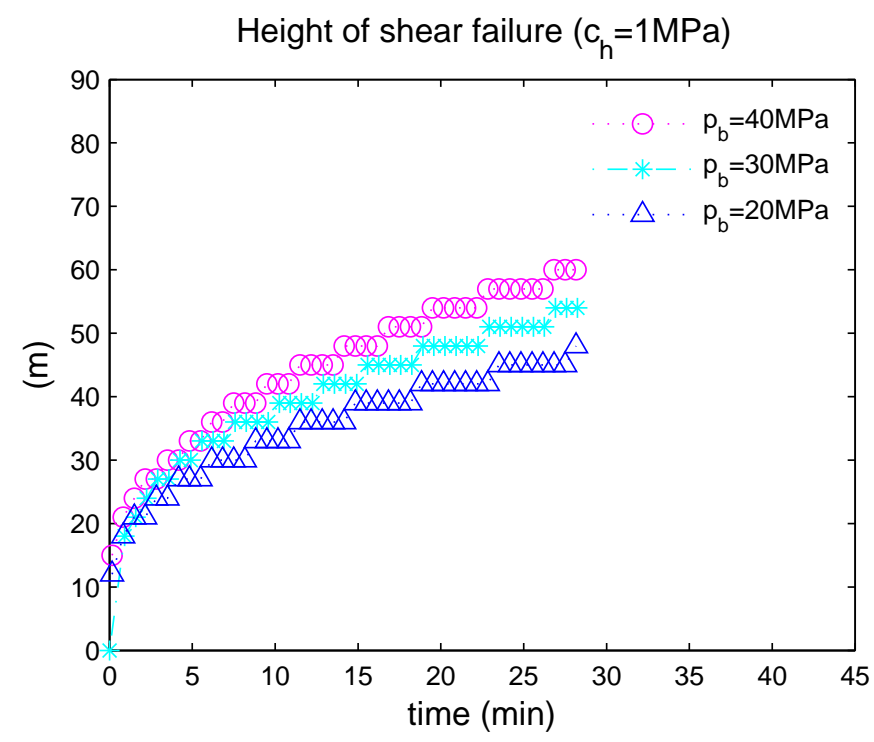

Figure 11: Failure propagation when the bottom pressure, $p_{b}$, becomes lower. Due to relaxed mechanical loading, the failure propagation for $p_{b}=20 \mathrm{MPa}$ becomes slow. 


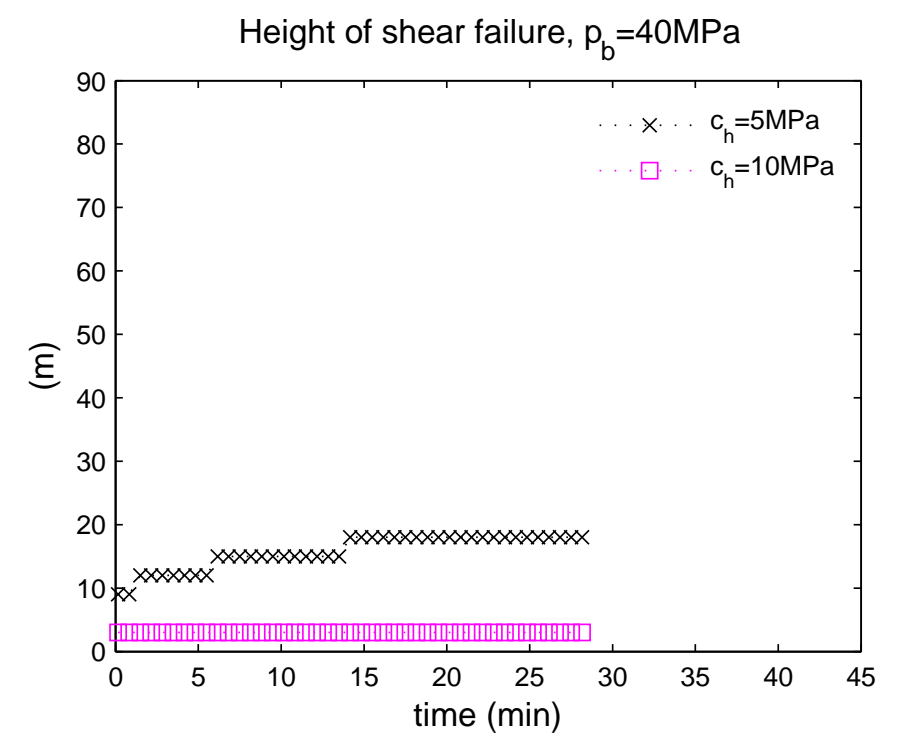

Figure 12: Failure propagation when $p_{b}$ becomes higher, i.e., 40MPa. Due to the increased mechanical loading, the failure propagation becomes faster than that of the reference case.
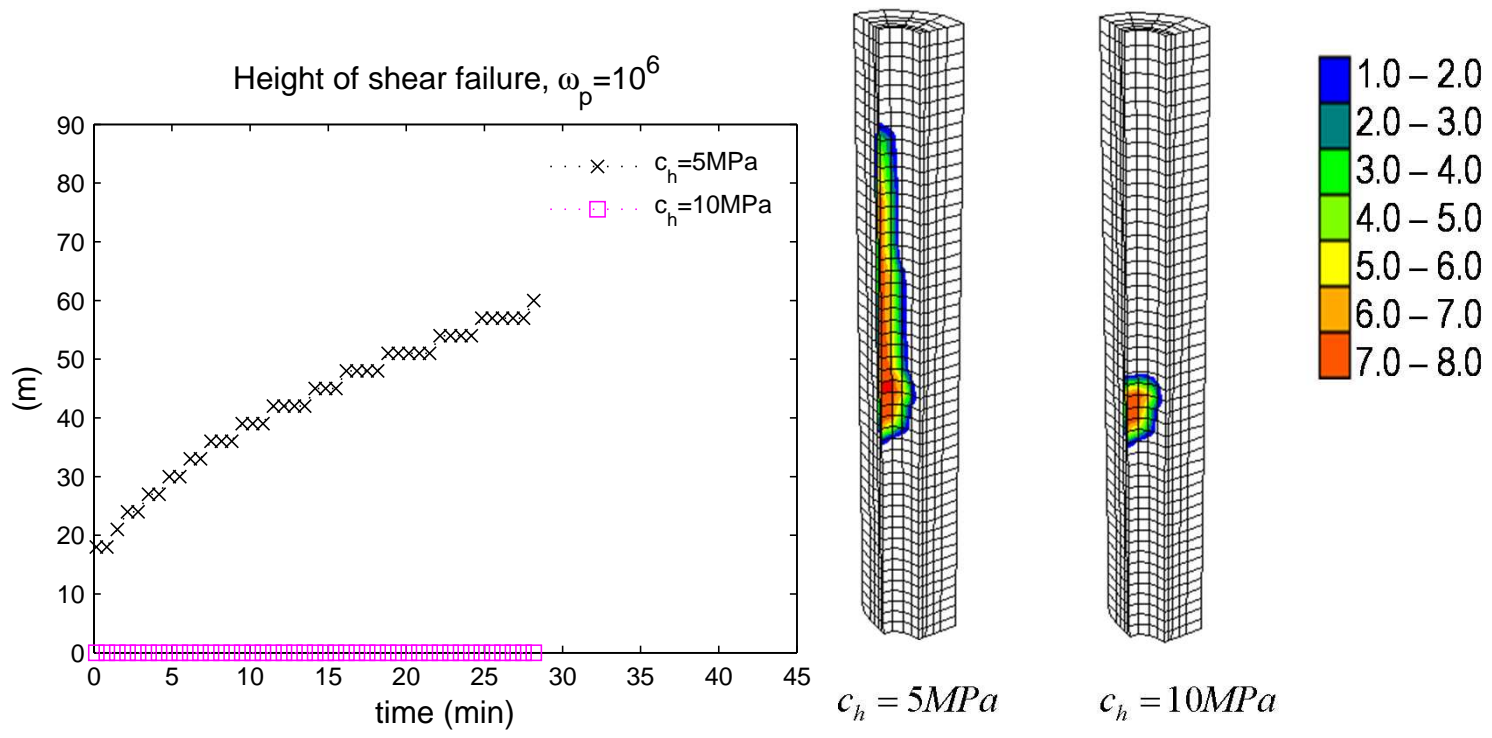

Figure 13: Failed areas of $c_{h}=5 M P a$ and $c_{h}=10 M P a$ when $\omega_{p}=10^{6}$. Compared to the reference case, $c_{h}=5 M P a$ causes larger failed zone, while $c_{h}=10 M P a$ still yields the same failed zone. 